\title{
Effects of preventive health services on survival of the elderly living in a community in Osaka,
} Japan

\author{
Noriyuki Nakanishi, Kozo Tatara, Toshio Tatatorige, Shigeki Murakami, \\ Fumiaki Shinsho
}

\begin{abstract}
Study objective - To examine the relationships between the use of preventive health services - such as health checks, basic health examination/cancer screening, and daily preventive health practices - and survival of elderly people living in
\end{abstract} the community.

Design and setting - A cohort of elderly people aged 65 years and over living in Settsu city, Osaka was followed for 38 months. Data on the history of health management, disability scores, and psychosocial conditions were collected in October 1992 by interview during home visits. Subjects - Of the 1491 people randomly selected from the computerised sex-age register at enrollment, 1473 were contacted and responses were obtained from 1405 (95.4\%). They constituted the study cohort. Follow up was completed for 1325 (94.3\%) (154 deceased and 1171 alive).

Measurements and main results - From the analysis using the Kaplan-Meier method and the log-rank test, female sex, younger age group (65-74 years), use of health checks, use of basic health examination and/or cancer screening, use of daily preventive health practices, less disability, taking part in social activity, and finding life worth living were univariately statistically significantly related to survival. The estimated survival rates were highest in those with regular health checks or daily preventive health practices before 59 years of age or both basic health examination and cancer screening. From the Cox proportional hazards model, use of health checks and use of daily preventive health practices remained as statistically significant factors associated with survival, controlling for other factors such as sex, age group, medical treatment, disability scores, and psycho-social conditions, and these hazard ratios (not used v starting at 59 years) were 0.41 (95\%CI, $0.25,0.66)$ and $0.52(95 \% \mathrm{CI}, 0.30,0.88)$, respectively.

Conclusions - Health management efforts such as health checks and daily preventive health practices may increase survival in the elderly.

(f Epidemiol Community Health 1997;51:199-204)
Today, Japan is a country with an 80 year life expectancy - the world's longest. In the coming 21 st century, Japan expects to become an extremely aged society with about one quarter of the population being elderly. ${ }^{1}$ In order to make the aged society of the 21 st century a society in which everyone is healthy and is able to live a secure life, an appropriate health care system has to be developed.

In keeping with a traditional post-war pattern of providing local preventive health services, ${ }^{2}$ the Japanese Government implemented the Health Services for the Elderly Act in 1983. Under this act, which is a key part of governmental efforts to prepare for the rapid increase in the absolute and relative numbers of elderly people projected for the near future, six preventive health services are provided free or at low charge by municipalities to all people in Japan who hold a resident card, are at least 40 years old, and are not offered periodical health examinations at their place of work. These preventive health services include the following and have been described in detail ${ }^{3}$ :

- Health examinations, including health checks as basic health examinations with special examinations when indicated, and screenings for stomach cancer, uterus cancer, breast cancer, lung cancer, and colon cancer (for uterus cancer and breast cancer screenings, women aged 30 or more are eligible),

- Issue of a health notebook,

- Health education,

- Individual health counselling,

- Rehabilitation programmes, and

- Home visit guidance.

Nationwide, the number of people who received basic health examinations was 9.77 million in 1993, accounting for $35.6 \%$ of eligible people. ${ }^{1}$ In that year, 4.37 million, 6.30 million, and 3.60 million people were screened for stomach cancer, lung cancer, and colon cancer, respectively in local health programmes. Altogether 4.13 million and 3.18 million women (aged 30 or more) were also screened for uterus and breast cancer, respectively. Total numbers of people who received health education, health counselling, rehabilitation, and home visit guidance were 11.71 million, 8.83 million, 1.99 million, and 0.89 million, respectively. These preventive health services under the act are key health care measures for maintaining and promoting the health of the residents who live in the community, especially the elderly. 
Currently, a salient question with regard to health care in Japan is how well preventive health services under the Health Services for the Elderly Act contribute to promoting better health and decreasing the mortality rate among the people in their prime of life. This study aims to investigate the factors associated with survival as health status in a community based sample of elderly people, with special reference to preventive health services.

\section{Methods}

SUBJECTS AND BASELINE DATA

On 1 October 1992, when this study was started, the city of Settsu, north Osaka, had a total population of 87293 , of whom 6674 were aged 65 years and over. A sample of 1491 people aged 65 years and over $(22.3 \%)$ was randomly selected from the computerised sexage register. Between 1 and 26 October 1992, all subjects in the survey population were visited at home and were interviewed with use of a questionnaire by 98 well-trained district welfare commissioners. Five people in the sample were found to have died and 13 had moved from Settsu city, so 1473 people were contacted. Responses were obtained from 1405 , a response rate of $95.4 \%$. Reasons for nonresponse were: absent (15 people); hospitalisation (25 people); placement in an institution (21 people); and refusal to participate (7 people). A total of 1405 people constituted the study population.

The questionnaire included items related to the following aspects and has been detailed elsewhere ${ }^{4}$ : (1) history of health management; (2) psycho-social conditions; and (3) health status as indicated by disability scores. For health management, we inquired into the history of day-to-day preventive health practices related to diet and exercise, attendance for regular health checks since youth (mainly at the work place) and basic health examination and cancer screening by Settsu city under the Health Services for the Elderly Act, and into current medical treatment. For assessing psycho-social conditions, our questionnaire asked about the elderly person's involvement in his/ her social network, the presence of activities considered as particularly meaningful, and about anxieties for the future. The question posed in the questionnaire is, 'Do you have Ikigai?' which could be translated directly as 'Do you have anything to live for?' It refers to particular aspects of one's life which make it meaningful or worth living.

For measuring disability, we adopted the concepts and methods developed by the Social Survey Division of the Office of Population Censuses (OPCS). ${ }^{5}$ Questionnaires are used to measure 10 main areas or types of disability locomotion, reaching and stretching, dexterity, seeing, hearing, personal care, continence, communication, behaviour, and intellectual functioning.

Each type of disability is scored on a scale from 0 , which represents no disability, up to a maximum which differs for each item, the highest number corresponding to the most severe grade of disability. Because multiple disabilities are frequent, the OPCS survey developed an overall severity score based on the following formula using the scores for the three worst disability scores for each person: worst +0.4 (second worst) +0.3 (third worst). In our study, we also adopted this method to arrive at an 'overall disability score'. The scores were grouped into four categories for analysis: no disability for an overall severity score of 0 , minor for that of 0.5-4.95, appreciable for that of 5-12.95, and severe for that of 13 and over.

\section{FOLLOW UP SURVEY}

People's status as of the end of November 1995 was surveyed from their resident registration cards and death certificates to verify their eligibility and outcome end points. Of the 1405 subjects enrolled in this study, follow up was completed for 1325 (154 deceased and 1171 alive) but not for the 80 who had moved from Settsu city by the time of follow up.

\section{STATISTICAL METHODS}

The survival times were calculated by using the date of enrollment and the date of death or the date of follow up (end of November 1995), or the date of last registration. Those who had moved from Settsu city during the follow up period have censored survival times, and those members of the cohort who were living in the city of Settsu at end of the follow up and who were still alive also have censored survival times.

The method of Kaplan-Meier ${ }^{6}$ was used to estimate the cumulative survival of the elderly according to the characteristics found from baseline data, and the log-rank test was used to assess the significance of the unadjusted difference in survival curves. Survival rates for pairwise comparisons were cumulative through the end of 38 months of observation. Multivariate analysis was performed by the Cox proportional hazards model $^{7}$ to identify subsets of independent prognostic factors for survival. A hazard ratio of 1 indicates that there is no difference between the subgroups: a hazard ratio $>1(<1)$ indicates that a person in the designated 'risk' subgroups is more (less) likely to die than a person in the designated baseline subgroup, given that all other determinants of survival are the same.

Data analysis was performed with the SPSS/ $P C$ statistical package (Marija J Norusis/SPSS Inc). All reported $p$ values are two-tailed and the level of significance is $\mathrm{p}<0.05$.

\section{Results}

\section{CHARACTERISTICS AT ENROLMENT}

Table 1 shows the basic characteristics of the elderly people at enrolment. The proportion of the subjects aged 75 years and over was higher among women than among men $(40.7 \% \mathrm{v}$ $34.8 \%)$. The percentages of those who had been receiving regular health checks or practising daily preventive health promotion, especially with regular health checks or daily 
Table 1 Characteristics of the elderly at baseline in relation to gender (values numbers of elderly (\% of group))

\begin{tabular}{|c|c|c|c|c|}
\hline Characteristics & Subclass & $\begin{array}{l}\text { Men } \\
(n=564)\end{array}$ & $\begin{array}{l}\text { Women } \\
(n=841)\end{array}$ & $\begin{array}{l}\text { Total } \\
(n=1405)\end{array}$ \\
\hline Age & $65-74 y$ & $368(65.2)$ & $499(59.3)$ & $867(61.7)$ \\
\hline \multirow{3}{*}{ Health checks } & $75+y$ & $196(34.8)$ & $342(40.7)$ & $538(38.3)$ \\
\hline & Not used & $105(18.6)$ & $241(28.7)$ & $346(24.6)$ \\
\hline & $\begin{array}{l}\text { Start at } 60+\mathrm{y} \\
\text { Start at } \leq 59 \mathrm{y}\end{array}$ & $\begin{array}{l}166(29.4) \\
293(52.0)\end{array}$ & $\begin{array}{l}291(34.6) \\
309(36.7)\end{array}$ & $\begin{array}{l}457(32.5) \\
602(42.8)\end{array}$ \\
\hline \multirow{3}{*}{$\begin{array}{l}\text { Basic health examination/ } \\
\text { cancer screening }\end{array}$} & Not used & $325(57.6)$ & 493 (58.6) & $818(58.2)$ \\
\hline & Only one used & $108(19.1)$ & $172(20.5)$ & $280(19.9)$ \\
\hline & Both used & $131(23.2)$ & $176(20.9)$ & $307(21.9)$ \\
\hline \multirow{3}{*}{$\begin{array}{l}\text { Daily preventative health } \\
\text { practices }\end{array}$} & No health practices & $336(59.6)$ & $582(69.2)$ & $918(65.3)$ \\
\hline & Start at $60+y$ & $86(15.2)$ & $129(15.3)$ & $215(15.3)$ \\
\hline & Start at $\leq 59 \mathrm{y}$ & $142(25.2)$ & $130(15.5)$ & $272(19.4)$ \\
\hline \multirow[t]{2}{*}{ Medical treatment } & No & $141(25.0)$ & $211(25.1)$ & $352(25.1)$ \\
\hline & Yes & $423(75.0)$ & $630(74.9)$ & $1053(74.9)$ \\
\hline \multirow[t]{4}{*}{ Disability* } & No & $258(46.7)$ & $287(34.7)$ & $545(39.6)$ \\
\hline & Minor & $184(33.3)$ & $366(44.3)$ & $550(39.9)$ \\
\hline & Appreciable & 78 (14.1) & $125(15.1)$ & 203 (14.7) \\
\hline & Severe & $32(5.8)$ & $48(5.8)$ & $80(5.8)$ \\
\hline Social activity & No & $274(48.6)$ & $568(67.5)$ & $842(59.9)$ \\
\hline & Yes & $290(51.4)$ & $273(32.5)$ & $563(40.1)$ \\
\hline \multirow[t]{2}{*}{ Life worth living (Ikigai) } & No & $93(16.5)$ & $155(18.4)$ & 248 (17.7) \\
\hline & Yes & $471(83.5)$ & $686(81.6)$ & $1157(82.3)$ \\
\hline \multirow[t]{2}{*}{ Anxiety } & No & $167(29.6)$ & $237(28.2)$ & $404(28.8)$ \\
\hline & Yes & $397(70.4)$ & $604(71.8)$ & $1001(71.2)$ \\
\hline
\end{tabular}

* Complete data for measuring an overall severity score were available for 552 men and 826 women. Disability was grouped into four categories: no disability for an overall severity score of 0 , minor for that of $0.5-4.95$, appreciable for that of $5-12.95$, severe for that of 13 and over.

Table 2 Survival rates of the elderly over 38 months by Kaplan-Meier method

\begin{tabular}{|c|c|c|c|c|}
\hline \multirow[t]{2}{*}{ Variable } & \multirow[t]{2}{*}{ Subclass } & \multicolumn{3}{|c|}{ Survival rate } \\
\hline & & $\%$ & $(95 \% C I)$ & $p$ value* \\
\hline Sex & $\begin{array}{l}\text { Men } \\
\text { Women }\end{array}$ & $\begin{array}{l}85.8 \\
91.2\end{array}$ & $\begin{array}{l}(82.9,88.7) \\
(89.3,93.1)\end{array}$ & 0.002 \\
\hline Health checks & $\begin{array}{l}\text { Not used } \\
\text { Start at } 60+y \\
\text { Start at } \leq 59 \text { y }\end{array}$ & $\begin{array}{l}82.9 \\
78.6 \\
90.8 \\
93.7\end{array}$ & $\begin{array}{l}(79.7,86.1) \\
(74.3,82.9) \\
(88.2,93.5) \\
(91.7,95.6)\end{array}$ & $<0.001$ \\
\hline $\begin{array}{l}\text { Basic health examination/ } \\
\text { cancer screening }\end{array}$ & $\begin{array}{l}\text { Not used } \\
\text { Only one used } \\
\text { Both used }\end{array}$ & $\begin{array}{l}86.1 \\
90.7 \\
95.4\end{array}$ & $\begin{array}{l}(83.7,88.4) \\
(87.3,94.1) \\
(93.1,97.8)\end{array}$ & $<0.001$ \\
\hline $\begin{array}{l}\text { Daily preventive health } \\
\text { practice }\end{array}$ & $\begin{array}{l}\text { No health } \\
\text { practices }\end{array}$ & 86.6 & $(84.4,88.8)$ & $<0.001$ \\
\hline & $\begin{array}{l}\text { Start at } 60+\mathrm{y} \\
\text { Start at } \leq 59 \mathrm{y}\end{array}$ & $\begin{array}{l}91.6 \\
95.2\end{array}$ & $\begin{array}{l}(87.9,95.3) \\
(92.7,97.8)\end{array}$ & \\
\hline Medical treatment & $\begin{array}{l}\text { No } \\
\text { Yes }\end{array}$ & $\begin{array}{l}91.8 \\
88.1\end{array}$ & $\begin{array}{l}(88.9,94.6) \\
(86.2,90.1)\end{array}$ & 0.055 \\
\hline Disabilityt & $\begin{array}{l}\text { No } \\
\text { Minor } \\
\text { Appreciable } \\
\text { Severe }\end{array}$ & $\begin{array}{l}93.6 \\
91.6 \\
82.8 \\
60.0\end{array}$ & $\begin{array}{l}(91.5,95.6) \\
(89.3,94.0) \\
(77.6,88.0) \\
(49.3,70.7)\end{array}$ & $<0.001$ \\
\hline Social activity & $\begin{array}{l}\text { No } \\
\text { Yes }\end{array}$ & $\begin{array}{l}85.5 \\
94.3\end{array}$ & $\begin{array}{l}(83.1,87.9) \\
(92.4,96.2)\end{array}$ & $<0.001$ \\
\hline Life worth living (Ikigai) & $\begin{array}{l}\text { No } \\
\text { Yes }\end{array}$ & $\begin{array}{l}79.8 \\
91.0\end{array}$ & $\begin{array}{l}(74.8,84.8) \\
(89.4,92.7)\end{array}$ & $<0.001$ \\
\hline Anxiety & $\begin{array}{l}\text { No } \\
\text { Yes }\end{array}$ & $\begin{array}{l}87.1 \\
89.8\end{array}$ & $\begin{array}{l}(83.9,90.4) \\
(87.9,91.7)\end{array}$ & 0.119 \\
\hline
\end{tabular}

* The difference between the curves was performed by the log-rank test. $\dagger$ Disability: no disability for an overall severity score of 0 , minor for one of $0.5-4.95$, appreciable for a score of $5-12.95$, severe
for a score of 13 and over.

preventive health practices before 59 years of age, were higher among men than women $(52.0 \%$ v $36.7 \%$ and $25.2 \%$ v $15.5 \%$, respectively). This is partly because men could have been given more opportunities of receiving regular health checks or been encouraged in day-to-day preventive health practices at their place of employment under the Industrial Safety and Health Law. There was no large difference between men and women in the proportions who had been receiving a basic health examination and/or cancer screening by Settsu city under the Health Services for the Elderly Act. Seventy five per cent were receiving medical treatment in both sexes. The proportion of those with a minor disability was higher among women than men $(44.3 \% \mathrm{v} 33.3 \%)$, but there was little difference between men and women in the percentages of those with appreciable or severe disability. As for psycho-social con- ditions, the proportion of those who took part in social activities was much higher among men than women $(51.4 \% \mathrm{v} 32.5)$. For both sexes, more than $80 \%$ and $70 \%$ respectively found life worth living and experienced anxiety about the future.

UNIVARIATE ANALYSIS FOR SURVIVAL

Table 2 shows the estimated survival rates of elderly people during the 38 months by the Kaplan-Meier method. The estimated 38 month survival rate for women was higher than that for men $(91.2 \% \vee 85.8 \%)$, and the curves between both sexes were significantly different by the log-rank test $(p=0.002)$. The estimated survival rates for those aged 65-74 years and for those aged 75 years and over were $92.9 \%$ and $82.9 \%$, respectively. This difference 


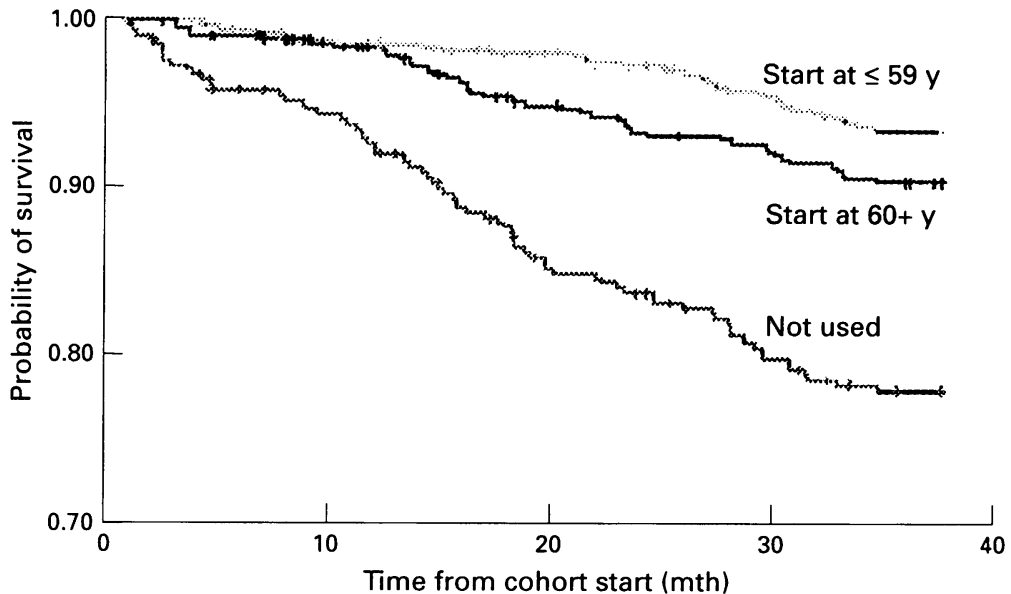

Figure 1 Kaplan-Meier survival curves in relation to the use of health checks. The tick marks indicate people alive at that interval. The difference between the curves was significant by the log-rank test $(p<0.001)$ : start health checks at $\leq 59$ years $v$ start at $60+$ years and health checks not used, $p=0.065$ and $p=0.001$ respectively; start health checks at $60+$ years $v$ health checks not used $p<0.001$.

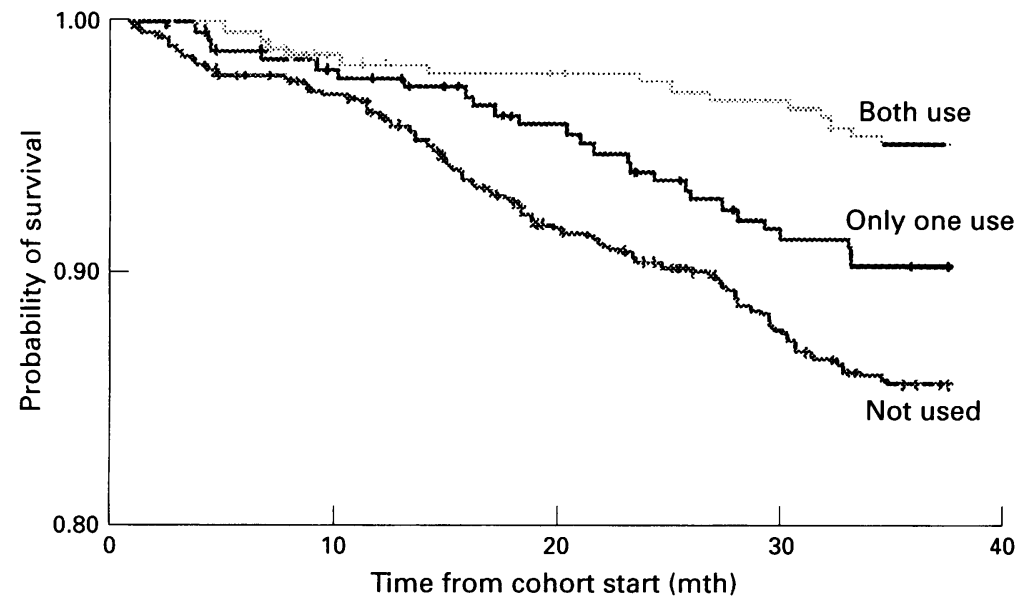

Figure 2 Kaplan-Meier survival curves according to use of the basic health examination and cancer screening. The tick marks indicate people alive at that interval. The difference between the curves was significant by the log-rank test $(p<0.001)$ : use of both $v$ only one used and not used $(p=0.023$ and $p<0.001$ respectively), only one used $v$ not used $(p=0.045)$.

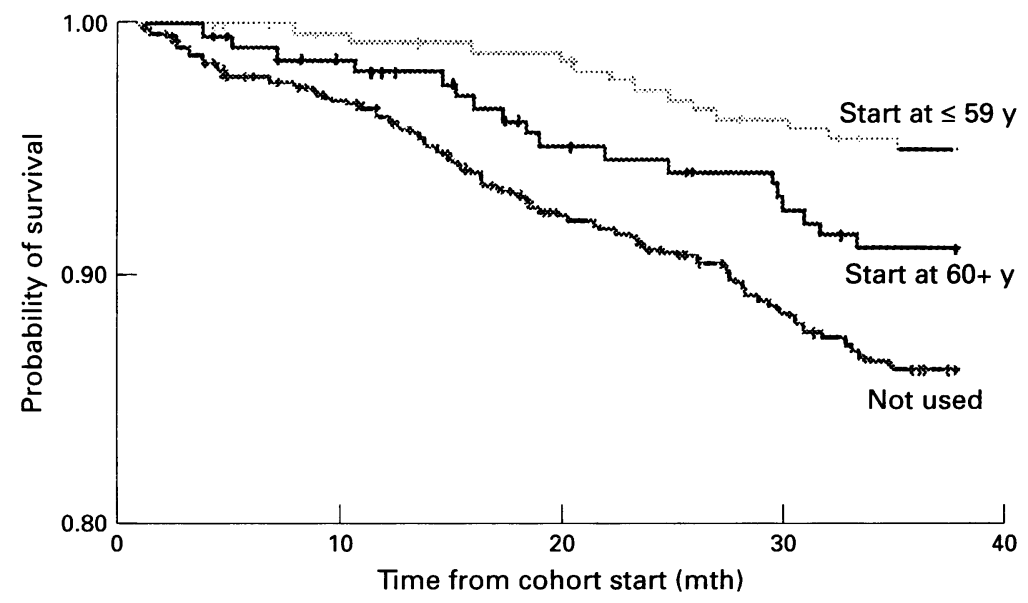

Figure 3 Kaplan-Meier survival curves according to the daily use of preventive health practices. The tick marks indicate people alive at that interval. The difference between the curves was significant by the log-rank test $(p<0.001)$ : start preventive practices at $\leq 59$ years $v$ start at $60+$ years and preventive practices not used $(p=0.081$ and $p<0.001$ respectively), start at $60+$ years $v$ preventive practices not used $(p=0.059)$. achieved statistical significance by the log-rank test $(\mathrm{p}<0.001)$.

Survival curves in relation to the histories of regular health checks since youth, basic health examination and/or cancer screening under the Health Services for the Elderly Act, and daily preventive health practices are shown in figures 1, 2, and 3, respectively. Each log-rank test of the three curves in relation to the history of health management showed a significant difference among these subclasses $(p<0.001)$. The estimated survival rates for the subjects who had been receiving regular health checks, had paid particular attention to their dietary and exercise regimens prior to 59 years, or had been receiving both the basic health examination and cancer screening were the highest $(93.7 \%, 95.2 \%$, and $95.4 \%$, respectively). The estimated survival rate for those with medical treatment was lower than that for those without (88.1\% v 91.8\%) and the curves among two groups achieved marginal statistical significance by the log-rank test $(p=0.055)$.

The estimated 38 month survival rate decreased with increasing disability and the curves for the four disability scores achieved statistical significance by the log-rank test $(p<0.001)$. As for psycho-social conditions, the estimated survival rates for those who took part in social activities or found life worth living were $94.3 \%$ and $91.0 \%$ respectively, while rates for those who did not were $85.5 \%$ and $79.8 \%$ respectively. Both these differences were statistically significant at $<0.001$ by the log-rank test. The estimated survival rate for those who experienced anxiety about the future was slightly higher than that for those who did not $(89.8 \% \mathrm{v} 87.1 \%)$, but there was no significant difference by the log-rank test $(p=0.119)$.

\section{MULTIVARIATE ANALYSIS FOR SURVIVAL}

The factors evaluated for their predictive value were assessed for their relationship to mortality by the Cox proportional hazards model (table 3). Statistically significant factors associated with survival were: female sex, younger age group (65-74 years), early use of health checks, early use of daily preventive health practices, and less disability. Calculations from $\beta$ statistic and standard error (SE) of these variables showed that hazard ratios for health checks (not used $\mathrm{v}$ starting at $\leq 59$ ), daily preventive health practices (no health practices $\mathrm{v}$ starting at $\leq 59$ years), and disability scores (no disability v severe) were 0.41 (95\% CI $0.25,0.66)$, $0.52(95 \%$ CI $0.30,0.88)$, and 3.80 (95\% CI $2.15,6.72)$ respectively.

\section{Discussion}

Several studies $^{8-13}$ have already demonstrated both theoretical bases and empirical evidence for causal links between some indicators and mortality in elderly people. Disability, self related health, life satisfaction, social support, and sociability appear to be stable predictive factors. Our study also showed a strong relation between disability scores and the risk of mortality. As for psycho-social conditions evaluated 
Table 3 Hazard ratios for mortality by Cox proportional hazards model

\begin{tabular}{|c|c|c|c|c|c|}
\hline Variable & $\beta$ & $S E$ & $\begin{array}{l}\text { Hazard } \\
\text { ratio }\end{array}$ & $(95 \% C I)$ & $p$ value \\
\hline $\begin{array}{l}\text { Sex } \\
\text { Age group } \\
\text { Health checks } \\
\text { Basic health examination/cancer screening } \\
\text { Daily preventive health practices } \\
\text { Medical treatment } \\
\text { Disability } \\
\text { Social activity } \\
\text { Life worth living (Ikigai) } \\
\text { Anxiety }\end{array}$ & $\begin{array}{r}-0.83 \\
0.40 \\
-0.45 \\
-0.14 \\
-0.33 \\
0.27 \\
0.44 \\
-0.42 \\
-0.14 \\
-0.29\end{array}$ & $\begin{array}{l}0.17 \\
0.18 \\
0.12 \\
0.14 \\
0.14 \\
0.22 \\
0.10 \\
0.23 \\
0.19 \\
0.18\end{array}$ & $\begin{array}{l}0.44 \\
1.49 \\
0.64 \\
0.87 \\
0.72 \\
1.31 \\
1.56 \\
0.65 \\
0.87 \\
0.75\end{array}$ & $\begin{array}{l}(0.31,0.61) \\
(1.05,2.12) \\
(0.50,0.81) \\
(0.66,1.15) \\
(0.55,0.94) \\
(0.85,2.02) \\
(1.29,1.89) \\
(0.42,1.02) \\
(0.60,1.28) \\
(0.53,1.08)\end{array}$ & $\begin{array}{r}<0.001 \\
0.027 \\
<0.001 \\
0.319 \\
0.016 \\
0.226 \\
<0.001 \\
0.061 \\
0.487 \\
0.118\end{array}$ \\
\hline
\end{tabular}

Variables and values of the study were as follows:

Sex: 1 for male, 2 for female.

Age group: 1 for $65-74$ years, 2 for $75+$ years.

Health checks: 1 for not used, 2 for $60+$ years, 3 for starting at $\leq 59$ years.

Basic health examination/cancer screening: 1 for not used, 2 for only one used, 3 for both used.

Daily preventive health practices: 1 for no health practices, 2 for $60+$ years, 3 for starting at $\leq 59$ years.

Medical treatment: 1 for no, 2 for yes.

Disability: 1 for no disability (overall severity score 0), 2 for minor (0.5-4.95), 3 for appreciable (5-12.95), 4 for severe (13 and over).

Social activity: 1 for no, 2 for yes.

Life worth living (Ikigai): 1 for no, 2 for yes
Lial activity: 1 for no, 2 for yes.

Anxiety: 1 for no, 2 for yes.

in this study, participation in social activities and the presence of particular meaningful aspects of life (Ikigai) were significantly related to the survival of the elderly by univariate analysis, and participation in social activities remained as a marginally significant predictive factor after multivariate analysis $(\mathrm{p}=0.061)$. Our results support some evidence that less disability, participation in social activities, and identification of particular aspects of life reflect an active physiological and psychological profile and a better adaptation to the environment and contribute to reducing the mortality of the elderly.

As for preventive health measures, the positive relationship between the whole spectrum of physical health and actual daily good health habits has been demonstrated. ${ }^{1415} \mathrm{~A}$ randomised trial in Copenhagen ${ }^{16}$ suggested that health checks at 3 month intervals resulted in reductions in mortality and lengths of hospital stay. A study in south Wales ${ }^{17}$ also showed an apparent reduction in mortality in one of two centres and other studies ${ }^{1819}$ have shown improvements in morale. But an early review of cost effectiveness studies of prevention pointed out that 'few prevention programs, if any, reduce medical expenditures' and that 'even when prevention costs less per person than acute care, its medical costs per unit of health can be as great or greater' ${ }^{20}$ Large randomised controlled trials in the USA and UK have also cast doubts on the benefits of screening and health checks, and they have come under critical scrutiny. ${ }^{2122}$ In Japan, even though such evidence that screening is beneficial was incomplete, the government started to provide preventive health services under the 1982 Health Services for the Elderly Act in 1983, on the assumption that health maintenance in middle aged people will promote better health and contribute to remaining healthy when these people become elderly.

Regarding the effects of preventive health services under the Health Services for the Elderly $A c t$, Tatara et $a l^{2324}$ reported on a nationwide survey that basic health examinations from middle age provided under the act are useful for reducing the demands for inpatient care of those 70 years of age or older, and that the use of basic health examinations stimulates the activities of other preventive health services such as cancer screening, health education, and health counselling. Nakanishi et $a l^{34}$ recently reported independent inverse associations between the use of health checks or basic health examinations under the act and the subsequent occurrence of disability in old age and the use of inpatient and outpatient care, and concluded that preventive health services may contribute to the health of the elderly and reducing the subsequent demand for medical care.

In this study survival analysis showed that the estimated survival rates were significantly higher among the subjects who had been receiving regular health checks, had paid particular attention to their dietary and exercise regimens or had been receiving basic health examination and/or cancer screening than among those who had not. These tendencies were more pronounced among those with regular health checks or daily preventive health practices before 59 years of age or among those who had taken advantage of both the basic health examination and cancer screening. From the multivariate analysis using the Cox proportional hazards model, early use of health checks and early practice of daily preventive health promotion remained as statistically significant factors associated with survival, controlling for other indicators such as sex, age, medical treatment, disability, and psycho-social conditions, which have already been identified in previous epidemiological research..$^{8-13}$

When examining the reasons for these results, at least three factors should be taken into consideration. One is that only restricted baseline data on general health and none on morbidity were included. The second is that the group of attenders at preventive health services had healthier status than non-attenders as indicated by 'activities of daily living' scores and disability scores. ${ }^{4}$ People who were already ill and knew what was wrong with them or patients with a severe disease would have a tendency to prefer medical services to preventive health services and may not attend preventive health services. The third factor is 
that the follow up period was too short (38 months) to allow causal conclusions, and further investigation may be needed to clarify whether preventive health services are simply associated with survival or contribute to or are responsible for improved survival.

The true benefits of any preventive health services are not the objective improvements in life and health, but the value people place on those improvements. So a measure of active life expectancy ${ }^{25}$ is also needed to identify indicators for improving the quality of life during the later years in terms other than death. Although mortality is chosen as the reference indicator in this study, our results suggest that preventive health services may be able to promote better health and reduce mortality among elderly people. The system of health management in Japan, based on general health checks followed by individual counselling and health education to stimulate preventive health habits, may contribute to better health in old age.

This study was supported in part by grants from the Department of Health Services for the Elderly, Ministry of Health and Welfare in Japan.

1 Health and Welfare Statistics Association. Kokumin eisei no doko 1995. (Trends in the nation's health, 1995). Tokyo: Kosei no shihyo, 1995 (in Japanese).

2 Tatara K, Shinsho F, Asakura S, Hashimoto M eds. ShiCho-Son no hoken jigyo. (Health services in cities, towns, and villages). Tokyo: Nihon Koshueisei Kyokai, 1984 (in Japanese)

3 Nakanishi N, Tatara K, Fujiwara $H$. Do preventive health services reduce eventual demand for medical care? Soc $S c i$ Med 1996;43:999-1005.

4 Nakanishi N, Tatara K, Takashima $Y$, et al. The association of health management with the health of elderly people. Age Ageing 1995;24:334-40.

5 Martin J, Meltzer H, Elliot D. The prevalence of disability among adults. OPCS surveys of disability in Great Britain. Report 1. London: HMSO, 1988.

6 Kaplan EL, Meier P. Nonparametric estimation from incomplete observations. 7 Am Stat Assoc 1958:53:457-81.

Cox DR. Regression models and life-tables. $\mathcal{F} R$ Stat Soc (B) $1972 ; 34: 187-200$.

8 Warren $M D$, Knight $R$. Mortality in relation to the functional capacities of people with disabilities living at home. $\mathcal{f}$ Epidemiol Community Health 1982;36:220-3.

9 Grand A, Grosclaude P, Bocquet H, Pous J, Albarede JL. Disability, psychosocial factors and mortality among the elderly in a rural French population. $\mathcal{f}$ Clin Epidemiol 1990;43:773-82.

10 Mossey JM, Shapiro E. Self-rated health: a predictor of mortality among the elderly. Am $\mathcal{f}$ Public Health 1982;72. 800-9.

1 House JS, Landis KR, Umberson D. Social relationship and health. Science 1988;241:540-5.

12 Sugisawa H, Liang J, Liu X. Social networks, social support, and mortality among older people in Japan. 7 Gerontol Soc Sci 1994;49:S3-13.

13 Berkman LF. Social networks, support and health: taking the next step forward. Am ₹ Epidemiol 1986;123:559-62.

14 Belloc N, Breslow L. Relationship of physical health status and health practice. Prev Med 1972;1:409-21.

15 Breslow L. Prospects for improving health through reducing risk factors. Prev Med 1978;7:449-58.

16 Hendriksen C, Lund E, Stromgard E: Consequences of assessment and intervention among elderly people: a three year randomised controlled trial. BMf $1984 ; 298: 663-8$.

17 Vetter NJ, Jones DA, Victor CR. Effects of health visitors working with elderly patients in general practice: a randomised controlled trial. BMF 1984;288:369-72.

18 Tulloch AJ, Moore V. A randomized controlled trial of geriatric screening and surveillance in general practice. $\mathcal{f}$ $R$ Coll Gen Pract 1979;29:733-42

19 McEwan RT, Davison N, Forster DP, Pearson P. Screening elderly people in primary care: a randomized controlled trial. Br $\mathcal{f}$ Gen Pract 1990;40:94-7.

20 Russell LB. The economics of prevention. Health Policy 1984;4:85-100.

21 Roworth MA. Screening in the elderly. Public Health 1989; 103:377-83.

22 Harris A. Health checks for people over 75: the doubts persist. $B M \mathcal{F}$ 1992;305:599-600.

23 Tatara $K$ Shinsho F, Suzuki M Takatorige $T$, Nakanishi N, Kuroda K. Relation between use of health check ups starting in middle age and demand for inpatient care by elderly people in Japan. $B M \mathcal{F} 1991 ; 302: 615-8$.

24 Tatara K, Shinsho F, Suzuki M, Takatorige T, Nakanishi $N$, Kuroda $K$. The effect of health services under the Health Service for the Elderly Act on inpatient care of the elderly. Fournal of Health and Welfare Statistics 1990;37: 23-30 (in Japanese).

25 Katz S, Branch LG, Branson MH, Papsidero JA. Active life expectancy. $N$ Engl $\mathcal{F}$ Med 1983;309:1218-24. 